\title{
Differentiation of Mathematics Examination at Two Levels for Higher Secondary CBSE Students in India: Study on Students' Satisfaction and Subject Related Perception
}

\author{
Navita Mahajan' ${ }^{1}$ Seema Garg ${ }^{2}$ \\ Amity University, Noida, Uttar Pradesh \\ Email Id: navitamahajan07@gmail.com ${ }^{1} \bullet$ seemagarg1@gmail.com $^{2}$
}

\begin{abstract}
The Central Board of Secondary Examination announced that Class 10 students will have two levels of mathematics papers from 2020.The name suggested for the two examinations will be Maths- Standard which will be same kind of existing level of examination, and Maths Basic, the standard that has been designed easier as compared Standard level. No proposed change in syllabus has been suggested, class room deliverables and internal assessment for both the levels of examination would remain the same. The standard level has been designed for the students who desire to pursue with mathematics at higher levels, while the basic level would be for the students who want to drop Mathematics after class ten and pursue other streams of Subjects. This study aims to find the satisfaction level of students with this format adopted for Mathematics and their attitude towards other subjects. The students were found to quite satisfy with the regulating so as teachers and parents. The satisfaction level was found to be quite high among all stake holders as this was found to be facilitating students in their interest areas for pursuing higher studies rather them making them burdened and stressed during Higher Secondary struggling with Mathematics. Not only this, the regulation also gave a greater clarity among students, if they were interested to pursue their higher studies with this or related subjects.
\end{abstract}

Key Words: Mathematics, CBSE, Standard, Regulation, Stress, Satisfaction.

\section{Introduction}

In January 2019, Central Board of School Education (CBSE) declared on having two varied levels of examination for Mathematics in order to meet the dissimilar learning requirements of 
the scholars. According to this, CBSE introduced a new version of the existing level of examination, which will be named as Mathematics-Basic and the current level will be named Mathematics-Standard. Regardless of having two question papers of varied difficulty levels, classroom teaching and internal valuation for students selecting for either of the levels would keep on to be the same.

The attempt is aimed at reducing the strain on students with a low aptitude for the subject. This is as well appropriate to scholars wishing to choose Arts or Humanities stream at the senior secondary level. Nevertheless, if after appearing and qualifying Mathematics-Basic examination a student desires to go in for Mathematics at the senior secondary level, he/she will be provided a choice to appear in Mathematics-Standard by the time of compartment exams in accordance with the rules.

If a student fails to qualify the annual examination, he/she shall have a choice to change the subject at the compartment examination in accordance with the rules of the Board according to the options given in the table below.

\begin{tabular}{|l|l|}
\hline In case of failure in & Compartment options \\
\hline Mathematics-Basic & Mathematics-Basic \\
\hline Mathematics-Standard & Mathematics-Standard Or Mathematics-Basic \\
\hline
\end{tabular}

The students, who have opted Mathematics-Basic and are able to qualify the exam, the student may opt for the Mathematics-Standard exam by the time of Compartment exams to improve their level of mathematics. After qualifying the Mathematics-Standard at Compartment exam, students will be qualified to select Mathematics at Sr. Secondary level.

Parents have different opinions about this as many parents do not want their children to overburden with stress they have been facing due this subject, while few are of the opinion that having Mathematics till Senior Secondary level enhances their skill of analysis for future growth and current digitization era, widens the scope of choosing different careers.

While on this other side, teachers also feel it's a good move that students have been given a choice to pick a level and this would make it more student centric rather than subject centric. Any student who does not want to pursue Mathematics will not be supressed with its fobia and have better concentration. 
The Human Resource Development (HRD) ministry too frames a panel in year 2018-19 to struggle a Maths phobia among students after National Assessment Survey revealed a "fear complex" among students on the subject. The survey concluded that learning levels for mathematics were comparatively on a lower progress among government school students as they promote from one class to another.

\section{Review of literature}

Novriani and Surya, 2017 described how students solve problems in solving problems. of mathematics. Class VIII. The study shows that students have problems solving problems that arise from interviews with teachers in the field of mathematics, such as: 1) Students have difficulty solving math problems while reading texts or questions 2) The students still do not understand the problem properly. 3) You do not understand the problem. Then they guess the answer to the problem. 4) The students do not want to find a solution to the problem. 5) Students have difficulty understanding the problem, they do not. You can interpret it as a symbol. Mohommad javed in his research "A Survey of Examination Phobia amongst Students at Secondary School Level" focuses on exam phobia among students. His study showed that the students suffer from exam phobia to some extent. Furthermore, the results revealed that the level of exam phobia in male and female students was same

K. Abdul Gafoor and Abidha Kurukkan 2015,illustrated in their study that $88 \%$ of selected mathematics was the topic they hated and that only $6 \%$ liked mathematics. The main reasons for rejecting mathematics were related to the difficulty in understanding the subject and the factors that affect the teacher or the lesson. While $20 \%$ rated mathematics as a very difficult subject, $54 \%$ said they had moderate difficulty, while only $10 \%$ rated it as a mild issue. Around $42 \%$ do not recognize the solutions given in their manual. A significant proportion of students use blind strategies to learn mathematics and have less adaptive beliefs about self-efficacy and epistemological beliefs.

K. Abdul Gafoor and Abidha Kurukkan 2016, Studies evidenced that teachers are accomplished of differentiating between students' use of self-regulated knowledge. In the case of maths outcomes in comparison to academic achievement in general, there are more studies among in Middle standard students, with a lesser but significant number of studies at secondary and tertiary level. Studies that focused on grades below five are only one, with recent studies shifting 
into nonconventional samples as primary students and tertiary students. Self-efficacy and test anxiety varies according to gender and subject

Bed Raj Acharya 2017, concluded in his study "Factors Affecting Mathematics Teachers' Learning Difficulties" that students, teachers and parents had an important role to play as key factors and as holders of Healthy Environment to improve the rate of success. The lack of connection between the new mathematical concept and the previously learned mathematical structure, the fear of mathematics, the negative attitude of mathematics, the economic situation and its educational origin, the administrative system of the school, the lack of infrastructures. and the lack of a teaching system has difficulties in learning mathematics.

Mrs. Gurpreet Kaur 2017, one the major basis cause poor performance in Mathematics is the related to poor teaching methodology adopted, low level of practice, conceptual weakness and a shortage of qualified mathematics teachers, the lack of adequate in-service training programmes, a lack of proper incentives for mathematics teachers, and an inherent fear of mathematics. The study discovered that math-phobia happens among students, which is characterized by nervous feelings in math class, difficulty in understanding math problem among others. Highlighted causes include poor student-teacher relationship, nonconductive environment for math class among others, distracting factors in the class who may be taking up tution classes outside and are not attentive in the class.

In general, students in Hong Kong have attached great standing to mathematics. Most found it motivating and took it as their much-loved topic. They had a general interest in mathematics schooling, but rarely participated in additional activities in mathematics. When they encountered difficulties, most quarrelled with their classmates and only a minority consulted their teachers. They expected others to teach them how to do it instead of copying others' solutions. Most students felt that mathematics is an issue that requires reflection. Most of them had problems understanding math lessons and solving their problems.

Cheng and Wong, 1991, were of the opinion that students' understanding of mathematics has lessened over the years. The average score for homesickness for a mathematics lesson increased from 2.68 on p.4 to 2.41 on p.6 (on a scale of 1 to 5). Similar results were found in articles such as "I do not want to learn math" (Wong, H.W., 1996). The degree of fondness for mathematics also declined as students rose to the rankings and many students found that mathematics courses 
were boring. Although most students liked math, considered it an important subject and were willing to learn math outside of school, many did not dare to learn math. As noted in many other studies, constant hard work and regularity was seen as the most important factor donating to success in mathematics. The most important reason for success in mathematics was attending a favourite school or finding a job.

Most students exhibited a optimistic attitude towards education of mathematics. For example, they agreed that the manual should be recited when listening to the teacher in class. They also found it important to understand the teacher's understanding and the underlying mathematical concept. They thought it was not enough to sit for the exam and that mathematics was something to think about. Many students chose teachers who assigned exercises outside the textbook and did not want to have less homework. They felt that good mathematicians took a broader learning initiative and did not limit their practice to this task

Schoolchildren did not anticipate that mathematics is an art, and majority of the sample thought that those good in mathematics were ingenious In alternative study, it was found that scholars alleged mathematics as problem solving by simple methods, as a subject taught in school having definite answers, as a subject of calculations, as a set of rules, as a subject that requires higher intellect, and as a advantageous subject yet with some portions not easily applicable to routine life

\section{Need and Significance of Study}

Mathematics is a subject that is not loved by everyone. Some people are passionate about the numbers and like to play with them while there is another set of people who have a strong averse for it. Different people have different learning abilities for this subject and need high level of hard work, practice and regular touch with the subject in order to excel. Here maximum contribution is being made by teacher who is aware of the learning difficulties of the students and can employ different strategies for different students. It has been studies, surveyed in many reports, researches that In January 2019, CBSE came out with regulation of introducing two level standards and this study aims to study the perspectives of different stakeholders associated with this, i.e Students, Teachers and parents also. 
: CiteFactor

\section{Methodology}

\section{$\underline{\text { Participants }}$}

A primary research was conducted on a sample of 150 students. A questionnaire was designed and distributed among the respondents. Likert scale was used to measure attitudes by asking people to respond to a series of statements about a topic, in terms of the extent to which they agree with them, and so tapping into the cognitive and affective components of attitudes. The sample includes the students of current class level $9^{\text {th }}, 10^{\text {th }}$ and $11^{\text {th }}$.

\section{$\underline{\text { Instruments }}$}

The feedback on two level mathematics was administered by obtaining data on factors like fondness for the subject Mathematics obtained by other factors like Subject related phobia, difficulty level of examination, teaching methodology of the subject, External pressure of performance (parents, teachers or others),faulty Time management, distractions ( friends, social media),Lengthy Syllabus, Fondness for another subject, satisfaction level with the ruling.

\section{Procedure}

The students were given the questionnaire and explained about the importance of it. They were asked about the facts they know about the Two standard Mathematics level. If have been explained earlier or sources they have come to know about it. The students were distributed the questionnaires and they were assured that their anonymity will be kept secret. Total one hour time was given to each student for understanding the questionnaire with

\section{$\underline{\text { Data Analysis }}$}

Linear regression analysis was used for finding the relationship between the dependent and independent variables of the research. The Cronbach's alpha test was performed to check the reliability of the data.

\section{Analysis}

The Cronbach's alpha value for the fondness related to subject was .710, stress level during exam was 0.69 and for the factors contributing to stress was calculated to be 0.821 . So, the data is considered reliable for further analysis. 
Among the 148 selected responses $55.4 \%$ (82) respondents were male while 44.6 (66) were female. $76.4 \%$ of the respondents were aware about the announcement of the two-level examinations for maths to be held by CBSE from 2020 whereas $23.6 \%$ didn't have prior knowledge of the same.

It was found that amongst all the subjects taught maths is the most disliked subject by the students. Such attitude towards the subject indicates the need for CBSE to take into notice the area of interest of the student and take steps for students to cope up with extra stress during the examination as well as on developing interest of the students in the subject.

$66 \%$ of the students agree to high level of stress felt by them during the mathematics examination followed by $52 \%$ students in social science and $47.3 \%$ students in science.

\section{The Model}

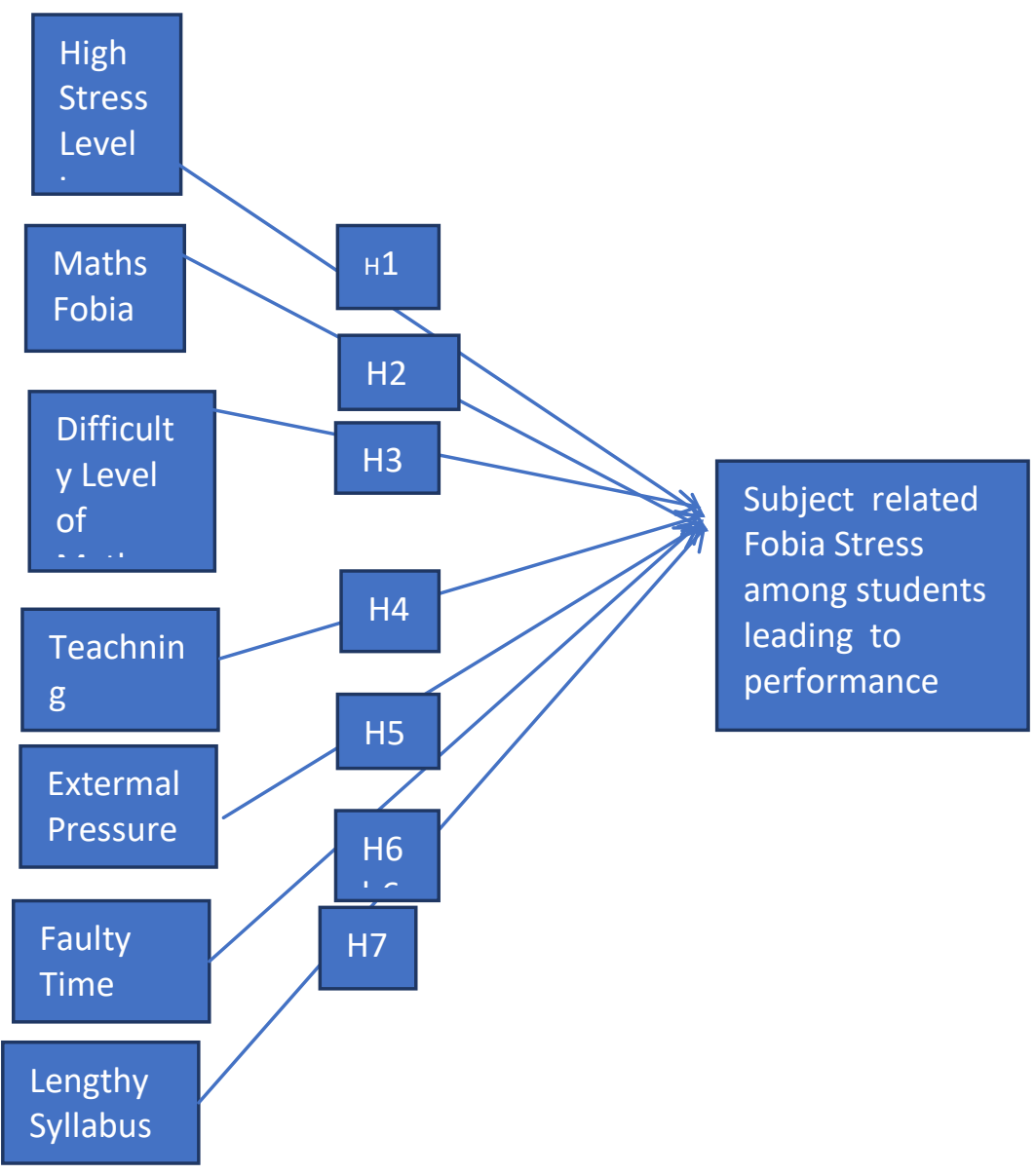

CBSE Two

Level Policy to

ease difficulty 
: CiteFactor

\section{The conceptual Model}

The results collected were analysed through Linear regressions and seven different Hypothesis were created for the testing of results.

Hypothesis 1: High stress level during examination does not impact the satisfaction level of students with the two-level examination as per CBSE guidelines

H0: High stress level during examination does not impact the satisfaction level of students with the two-level examination as per CBSE guidelines

HI high stress level during examination impacts the satisfaction level of students with the twolevel examination as per CBSE guidelines

Result: The mean square value (.625) is found to be higher than the significant value(.453) thus, the alternate hypothesis is selected.

Hypothesis 2: Maths Subject related phobia as a contributing factor to stress level during exams

H0: Subject related phobia as a contributing factor to stress level during exams does not impact the satisfaction level of students with the two-level examination as per CBSE guidelines

HI Subject related phobia as a contributing factor to stress level during exams impacts the satisfaction level of students with the two-level examination as per CBSE guidelines

Result: The mean square value (16.024) is found to be higher than the significant value (.00) thus, the alternate hypothesis is selected.

Hypothesis 3: Difficulty level of Mathematics examination as a contributing factor to stress level during exams

H0: Difficulty level of examination as a contributing factor to stress level during exams does not impact the satisfaction level of students with the two-level examination as per CBSE guidelines

HI Difficulty level of examination as a contributing factor to stress level during exams impacts the satisfaction level of students with the two-level examination as per CBSE guidelines

Result: The mean square value (13.40) is found to be higher than the significant value (.00) thus, the alternate hypothesis is selected. The high mean square value infers that Difficulty level of examination as a contributing factor to stress level during exams is one of the major predictors to 
satisfaction level with the announcement of two level mathematics examination amongst the students

Result: Majority of students (i.e.63\%) agree that difficulty level of examination is a factor that causes stress during exams. Such students are sure to be benefitted by the provision of choice of difficulty level in the $10^{\text {th }}$ board examination as announced by CBSE.

Hypothesis 4: Teaching methodology of the subject as a contributing factor to stress level during exams does not impact the satisfaction level of students with the two-level examination as per CBSE guidelines

H0: Teaching methodology of the subject as a contributing factor to stress level during exams does not impact the satisfaction level of students with the two-level examination as per CBSE guidelines

HI Teaching methodology of the subject as a contributing factor to stress level during exams impacts the satisfaction level of students with the two-level examination as per CBSE guidelines

Result: The mean square value (12.62) is found to be higher than the significant value (.001) thus, the alternate hypothesis is selected. The high mean square value infers teaching methodology of the subject as a contributing factor to stress level during exams is one of the major predictors to satisfaction level with the announcement of two level mathematics examination amongst the students. Teaching methodology decides level of learning with the introduction of two level examination in mathematics the students will have an option to match his level of learning with the level of difficulty of the examination thus decreasing extra stress.

Hypothesis 5: External pressure of performance (parents, teachers or others) as a contributing factor to stress level during exams

H0: External pressure of performance (parents, teachers or others) as a contributing factor to stress level during exams does not impact the satisfaction level of students with the two-level examination as per CBSE guidelines

HI External pressure of performance (parents, teachers or others) as a contributing factor to stress level during exams impacts the satisfaction level of students with the two-level examination as per CBSE guidelines 
Result: The mean square value (12.011) is found to be higher than the significant value (.001) thus, the alternate hypothesis is selected. with an option to choose the difficulty level of the examination the students have a higher probability to score more in the examinations which will help them improve their overall result henceforth helping them to cope up with external pressure of performance.It can be observed that majority of students feel stressed out during exams due to external pressure of performance by parents, teachers or others. Hence, improving of overall result due to the option of choosing difficulty level of exam will result $n$ decreasing such sense of external pressure of result.

Hypothesis 6: Faulty time management causing stress during exams

H0: Faulty time management as a contributing factor to stress level during exams does not impact the satisfaction level of students with the two-level examination as per CBSE guidelines

H1 Faulty time management as a contributing factor to stress level during exams impacts the satisfaction level of students with the two-level examination as per CBSE guidelines.

Result: The mean square value (4.229) is found to be higher than the significant value (.050) thus, the alternate hypothesis is selected. Comparatively less time is required to understand easy concepts and prepare for an easier level of difficulty in in certain subjects that students find difficult. This will provide students with extra time to prepare for other subjects and will help to decrease the stress level during exam created by shortage of time to study. As observed from the data majority of students agree that faulty time management during exam time is a reason causing extra stress, the idea of providing two difficulty level of examination according to their choice will help the students perform better on an overall level.

Hypothesis 7: Lengthy syllabus as reason causing stress during exams

H0: Lengthy syllabus as a contributing factor to stress level during exams does not impact the satisfaction level of students with the two-level examination as per CBSE guidelines

H1. Lengthy syllabus as a contributing factor to stress level during exams impacts the satisfaction level of students with the two-level examination as per CBSE guidelines

Result: The mean square value (2.560) is found to be higher than the significant value (.128) thus, the alternate hypothesis is selected. 
As the difficulty level of exam decreases lengthy syllabus can be taught and learned easily and in time. This will help students to perform better in the examination at the level of difficulty chosen by students, thus impacting the satisfaction level by the two-level exam as announced by CBSE among students.

\section{ANOVA Table}

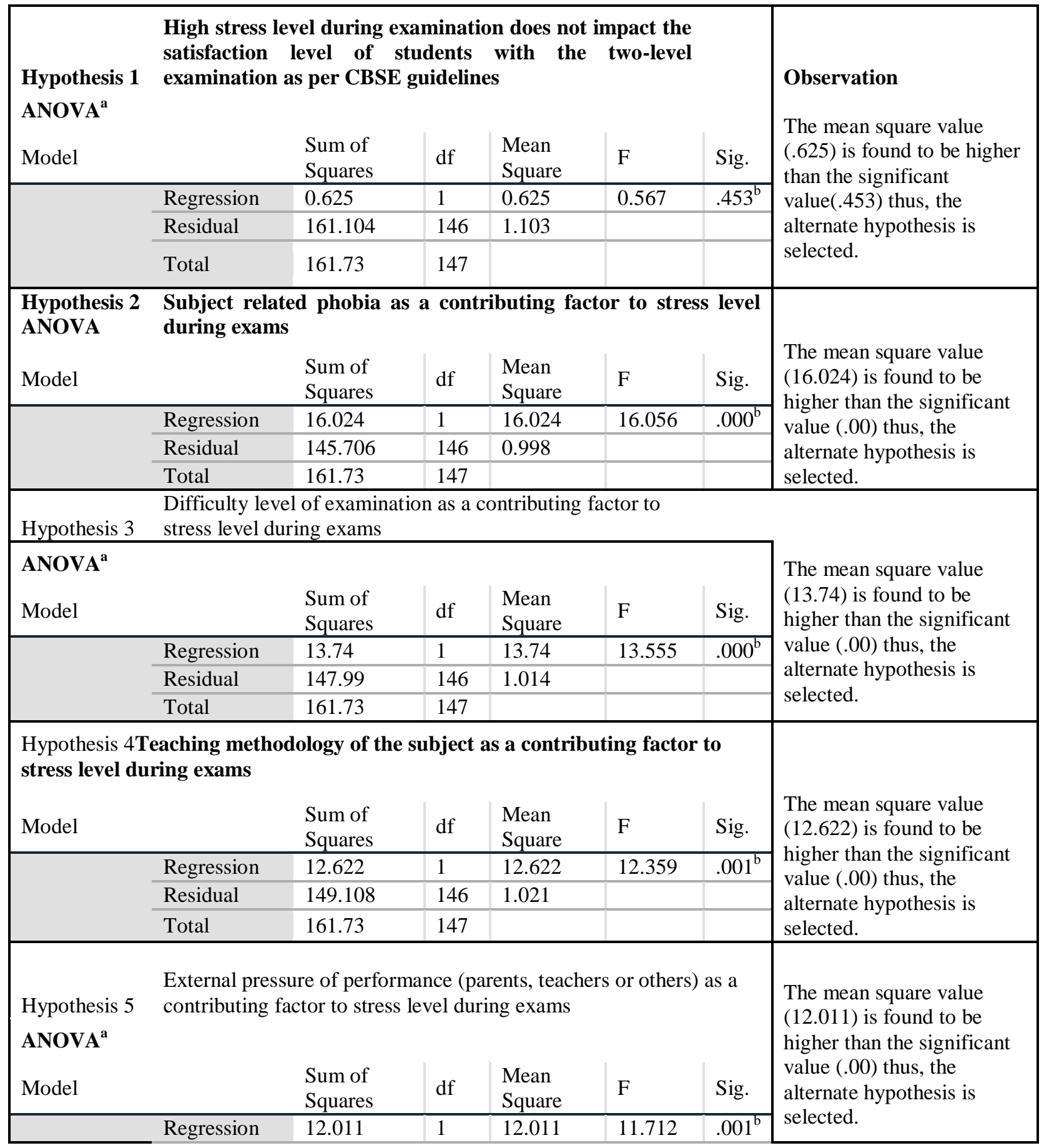




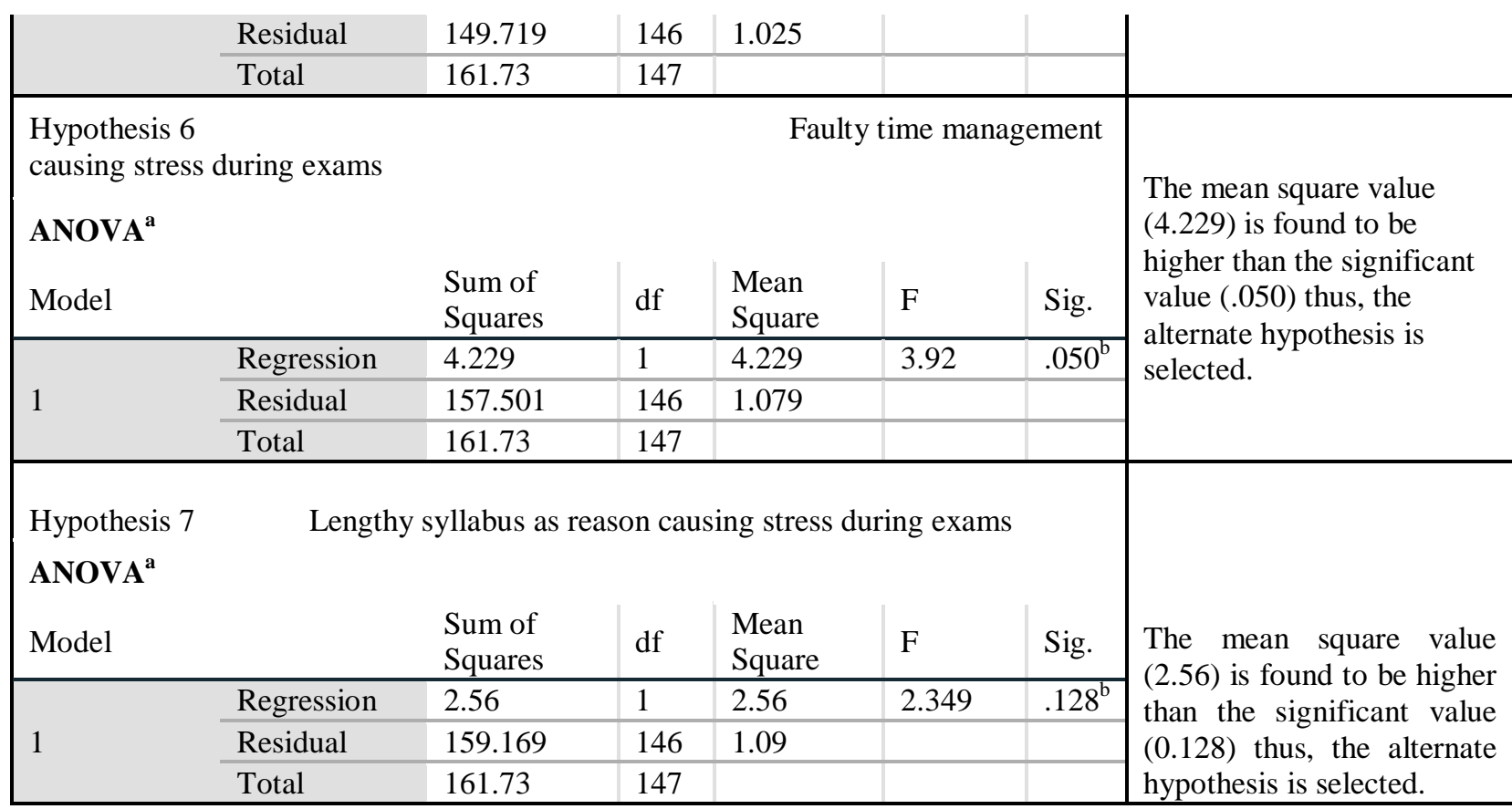

\section{Affinity of the students to subject they want to pursue for their higher education}

Majority of students want to pursue career in science, English and maths respectively. But for the students who want to pursue maths as their subject for higher education the difficulty level of the paper remains unchanged. This will ensure the quality of the result for students pursuing Mathematics. The new pattern without disturbing the students wanting to make a career in maths would aid the students taking up different subjects in future. It would help them cope up with extra stress and phobia related to maths and improve their overall result as well.

Satisfaction level towards the two level exams as announced by CBSE (i.e. Mathematics-

\section{Standard Or Mathematics-Basic)}

Majority (65\%) of students believe that the declaration of this exam will bring satisfactory results among students while $11 \%$ of the students do not find the new guidelines satisfactory. Thus, indicating more probability of success of this scheme and expected to reduce the level of stress and will match the level of learning and testing. The students have their hopes high for the success of this pattern of examination.

\section{Overall Students View on CBSE Regulation}

Majority of respondents are in favour of the new guidelines and think it can prove to be a good step in education. However, $42 \%$ respondents believe that it is a good step but it should be tested 
before taking a permanent decision. This indicates the satisfaction level among the students for the new guidelines and the future prospects of its success. The above data also represents the new hope that is created by the option of choosing the difficulty level of exam based on the learning and affinity towards the subject.

\section{Other Opinion from Students:}

The students were not satisfied with the curriculum of Mathematics as they feel that some of the chapters should be revised and curriculum should be designed from practical point of view. The syllabus should be more oriented towards the career options they will choose in future. Aspects related to banking, finance, GST, Taxes, accounting should be added from Ninth Standard only. The content related to Geometry, Trigonometry and constructions should be reduced to some extent as the application of these topics is comparatively less in further fields except Engineering. Also as students are aspiring to appear for higher competitive examinations like CAT, MAT other Management Domain Exams, so the application and coverage of topics like banking, Finance ,sales tax, GST , Interest rates in being seen more in these exams, hence students want higher skills in class Nine and Ten to get hand on to these topics.

\section{Teachers' View}

Around 30 teachers were also interviewed for this and mostly everyone welcomed this step of CBSE. The overburdened stress, difficulty of coping with the subjects and arrangement of external help sometimes that cause extra financial burden were some of the reasons. Also the contrary students who may not find it interesting to study Mathematics and have different goals altogether may clear the basis level and can carry on with the subjects on a more successful way in their future career.

\section{Parents View}

Parents were found to be most relaxed and over joyous with this regulation and they welcomed it with full support. Earlier parents whose children were not able to cope up with this subjects had a lot of stress level in them too as it could have lowered the overall grade of student and also it was becoming more of like a phobia for the children.

As Children were not willing to pursue it on higher level, it was worrisome situation for parents to counsel and focus their children on this subject in the board class as not only the difficulty 
level was high but due to this more time was being consumed by this subject which was taking a toll on others as well due to less time available for them.

Also CBSE has given the option that if a child still wants to take up Mathematics in Eleventh class and has passed it in Basic Level in class Ten, he would be given a chance to clear it in Supplementary Examination held in July for Class ten.

\section{Discussion of Results}

The data suggests that amongst all the subjects taught maths is the most disliked subject by the students and majority of students agree to high level of stress felt by them during the mathematics examination. Thus, the declaration of the two diverse level of examination can be considered as an aid to all such students.

Subject related phobia highly contributes to the stress level in the exams. The present level subject related phobia is likely to be reduced after the implementation of the new format of examination, thus, increasing the satisfaction level amongst students regarding the same.

Majority of students (i.e.63\%) agreed that difficulty level of examination is a factor that causes stress during exams. Such students are sure to be benefitted by the provision of choice of difficulty level in accordance to their learning in the $10^{\text {th }}$ board examination as announced by CBSE.

With an option to choose the difficulty level of the examination the students have a higher probability to score more in the examinations which will help them improve their overall result henceforth helping them to cope up with external pressure of performance which makes it a favourable step for students.

Majority of students agree that faulty time management during exam time and lengthy syllabus is a reason causing extra stress. Comparatively less time is required to understand easy concepts and prepare for an easier level of difficulty in in certain subjects that students find difficult. This will provide students with extra time to prepare for other subjects and will help to decrease the stress level during exam created by shortage of time to study.

As the difficulty level of exam decreases lengthy syllabus can be taught and learned easily and in time. This will help students to perform better in the examination at the level of difficulty chosen by students. Thus, impacting the satisfaction level by the two-level exam as announced by CBSE 
among students. The majority of students want to pursue career in science, English and maths respectively. But for the students who want to pursue maths as their subject for higher education the difficulty level of the paper remains unchanged. This will ensure the quality of the result for students pursuing Mathematics. which makes it a good decision.

The students seem to be quite satisfied with the new patter of examination and have high hopes with the same. so it can be concluded that this format of examination is a good step to decrease the stress level in students. Students sure have their hopes high with new exam pattern as announced by CBSE and agree that it should be continued but a large part of the sample is of the opinion that the project must be testwd before taking any permanent decision.

Overall this announcement about the two level exams as announced by CBSE (i.e. MathematicsStandard or Mathematics-Basic) is a good step towards a better and stress free education system.

\section{Limitations}

The sample is taken from atomic energy central school Kakrapar site only. More number could have been enhanced. PAN India study can be conducted.

The students of Private and public schools might have a different opinion. with variation of demographics (rural vs urban population etc.) the outcomes of the study might change owing to availability of infrastructure and other teaching aids.

\section{$\underline{\text { References }}$}

Acharya B. Raj. (2017). Factors Affecting Difficulties in Learning Mathematics. Mathematics Learners International Journal of Elementary Education (6). doi: 10.11648/j.ijeedu.20170602.11. pub 2

Bandura, A. (1977). On Self-efficacy: Toward a unifying theory of behavioural change. Psychological Review, 84, 191-215.

Briggs, J. (1994). What are effective schools? Lessons from East and West. The Radford Memorial Lecture. (pp 19-39). Australian Educational Researcher.

Cheung, P.H. (1994). Restructuring secondary school mathematics syllabuses. On Mathematics Syllabuses Review. Joint Working Party for Revision.

Cheng, S. C. \& Wong, N. Y. (1991a). The attitudes towards learning mathematics among Hong Kong secondary school students. CU Education Journal, 19, 13-18.

Fraser, J.B. (1998). Science learning environments: assessment, effects and determinants. In. B.J.Fraser, and K.G. Tobin (Ed.s). International Handbook of Science Education, Vol. 1, (pp 527-564). Dordrecht: Kluwer Academic Publishers. 
Fung, C.I. (1996). On Curriculum reform in mathematics and the Target Oriented Curriculum. Education Journal, 23(2), 125-150.

Fung, C.I., \& Wong, N.Y. (1997). (Unofficial) Mathematics Curriculum for Hong Kong, (pp P.1 to S.5). Hong Kong: Hong Kong Association for Mathematics Education.

Gafoor, K. Abdul \& Kurukkan, A. (2015). Why High School Students Feel Mathematics Difficult? An Exploration of Affective Beliefs, Paper presented. In UGC Sponsored National Seminar, Pedagogy of Teacher Education- Trends and Challenges. Kozhikode, Kerala. Farook Training College.

Gafoor, K. Abdul \& Kurukkan, A. (2016). Self-Regulated Learning: A Motivational Approach for Learning Mathematics. International Journal of Education and Psychological Research (IJEPR),5, I 3 .

Hau, K.T., \& Salili, F. (1991). On Structure and semantic differential placement of specific causes: Academic causal attributions by Chinese students in Hong Kong. International Journal of Psychology,26, 175-193.

Hau, K.T., \& Salili, F. (1996). Achievement goals and causal attributions of Chinese students. In S.Lau (Ed.). Growing Up the Chinese Way (pp121-145). Hong Kong: The Chinese University Press.

Ho, M.F. (1996). Communication in the mathematics classroom (Unpublished M.Ed. thesis). The University of Hong Kong, Hong Kong.

Kaur, G. (2017), On Math-Phobia: Causes and Remedies. International Journal for Research in Applied Science \& Engineering Technology (IJRASET). 5, I 6.

Rizky, M. Novriani \& Surya, E. (2017). Analyzing the Difficulties of Students in Mathematics. Journal of Sciences \& Basic Research.

Times of India. (2019, January 12). CBSE eases 'math burden' on students: Hyderabad News. Retrieved July 17, 2019, from https://timesofindia.indiatimes.com/city/hyderabad/cbse-eases-math-burdenon-students/articleshow/67494935.cms

Times of India. (2019, January 13). Cbse: Will new CBSE rule bring hope to Gujarat students?: Ahmedabad News. Retrieved July 17, 2019, from https://timesofindia.indiatimes.com/city/ahmedabad/will-new-cbse-rule-bring-hope-to-gujaratstudents/articleshow/67506886.cms

Times of India. (2019, January 12). Numbers failed to add up for easy maths option in Maharashtra: Nagpur News. $\quad$ Retrieved July 17, 2019, from https://timesofindia.indiatimes.com/city/nagpur/numbers-failed-to-add-up-for-easy-maths-optionin-maha/articleshow/67494444.cms

Times of India. (2019, January 12). To help students pass, CBSE devises new math formula: Nagpur News. Retrieved July 17, 2019, from https://timesofindia.indiatimes.com/city/nagpur/to-helpstudents-pass-cbse-devises-new-maths-formula/articleshow/67494260.cms 